\title{
Teoría y política de Otto Bauer sobre el imperialismo y las crisis (1904-1914)
}

\author{
Otto Bauer's Theory and Politics on Imperialism and Crises (1904-1914)
}

\author{
Manuel Quiroga* \\ Darío Scattolini** $^{* *}$
}

Resumen: En esta obra analizaremos las posiciones teóricas y políticas de Otto Bauer (intelectual austríaco, miembro del Partido Social Demócrata de Austria y de la escuela llamada Austro-marxista) sobre la teoría de las crisis y la cuestión del imperialismo en el marco la Segunda Internacional. En primer lugar analizaremos su formulación de la teoría marxista de las crisis en forma de una teoría del ciclo industrial. En segundo lugar analizaremos su formulación de una teoría del imperialismo durante su intervención en el debate sobre las nacionalidades en la Social Democracia austríaca, así como su recepción de las obras canónicas de Hilferding y Luxemburg sobre el tema. Finalmente, consideraremos su intervención política en torno al Estado austríaco, su política exterior y los conflictos nacionales que se desarrollaron en su seno (y su impacto en su partido). Todo el análisis será sustentado a través del examen de fuentes primarias. Nuestra hipótesis es que existió una relación orgánica entre los tres aspectos analizados: una posición donde las crisis eran un fenómeno únicamente cíclico favoreció una concepción del imperialismo como una política particular que no era intrínsecamente necesaria para el desarrollo del capitalismo. En el terreno político esto condujo a una postura que preconizaba el mantenimiento del statu quo de la configuración estatal austríaca, que fue modificada sólo gradual y tardíamente debido al impacto de los conflictos nacionales y la evolución del imperialismo austríaco y europeo en general. En la conclusión juzgamos en detalle esta idea recapitulando los distintos temas de nuestro trabajo.

Palabras clave: Otto Bauer, Teoría de las crisis, Imperialismo, Segunda Internacional, Socialismo, Partido Social Demócrata de Austria

\begin{abstract}
In this work we will analyze the theoretical and political positions of Otto Bauer (an Austrian intellectual, member of the Social Democratic Party of Austria and of the so called Austro-marxist school) on crisis theory and the issue of imperialism in the framework of the Second International. Firstly, we will analyze his formulation of Marxist crisis theory as a business cycle theory. Secondly, we will study his formulation of a theory of imperialism during his intervention in the debate on nationalities in Austrian Social Democracy, as well as his reception of the canonical works of Hilferding
\end{abstract}

\footnotetext{
* Argentino, Licenciado en Historia, Becario Doctoral del CIECS-CONICET en Córdoba, Programa de Historia Contemporánea, manuelquirogasoto@gmail.com

** Argentino, Licenciado en Filosofía, Universidad Nacional de Córdoba, esfilo@ffyh.unc.edu.ar
} 
and Luxemburg on the subject. Finally, we will consider his political intervention on the Austrian State, its foreign policy, and the national conflicts that developed inside it (and the impact of all these elements on his Party). Our hypothesis is that an organic relationship existed between these aspects: a position that considered crisis solely as a cyclical phenomenon favored a conception of imperialism as a particular policy that was not intrinsically necessary for the development of capitalism. In the political terrain this led to a stance that upheld the status quo of the Austrian State configuration, which was modified only gradually and belatedly, owing to the impact of national conflicts and the general evolution of Austrian and European imperialism. In our conclusion we will judge this idea in detail summing up the different subjects of our work.

Keywords: Otto Bauer, Crisis theory, Imperialism, Second International, Socialism, Social Democratic Party of Austria

Recibido: 18 abril 2016

Aceptado: 29 julio 2016

\section{Introducción}

En el presente artículo analizamos las contribuciones de Otto Bauer, teórico de la llamada escuela Austro-marxista, al problema del análisis de las crisis y el imperialismo. Ambos fueron dos de los tópicos de debate más importantes para los teóricos marxistas de la época, e intentaremos demostrar que estaban estrechamente ligados en las concepciones de Bauer. Estos aspectos serán abordados entrecruzando un análisis interno de sus desarrollos teóricos con una consideración del contexto de su producción. Tratándose de un intelectual de partido, que además tuvo una influencia teórica internacional considerable, resulta inevitable poner en consideración la política de la Social Democracia austríaca para evaluar la actuación de Bauer en el marco de ella y de las disputas a nivel internacional entre las tendencias de la Social Democracia -como se llamaban en esa época los partidos que adherían al marxismo (con distintas tendencias internas reformistas, revolucionarias o centristas) y la Segunda Internacional que los agrupaba.

Todo el análisis será sustentado por el examen de fuentes primarias, especialmente los escritos de Bauer sobre estos temas, complementadas por bibliografía secundaria para incluir textos suyos que no tenemos disponibles y para contextualizar el análisis con aspectos relevantes de la vida de su partido y de la Segunda Internacional.

En la primera sección nos centramos en su artículo más temprano sobre las crisis, "La teoría de las crisis económicas de Marx", de 1904. Primero presentamos el contexto del sobre las crisis en la Social Democracia, y luego exponemos en detalle la teoría del ciclo industrial formulada por Bauer, señalando algunas críticas. 
En la segunda sección analizamos su teoría del imperialismo. Su presentación más acabada del problema del imperialismo se encuentra en clásico trabajo La cuestión de las nacionalidades y la Social Democracia. En esa obra Bauer pretendía proponer y fundamentar una política para abordar la cuestión nacional en el Imperial Austro-húngaro, que estaba habitado por una docena de nacionalidades distintas. El desarrollo de la posición de Bauer sobre el imperialismo surgió como un tema subordinado a la cuestión nacional. Por lo tanto, comenzamos esta sección con una reconstrucción sumaria de los debates sobre la cuestión nacional y la postura de Bauer al respecto. Luego analizamos la posición de Bauer sobre el imperialismo en La cuestión de las nacionalidades. Finalmente consideramos su recepción de los dos aportes fundamentales a la teoría del imperialismo en la Segunda Internacional: El capital financiero (Hilferding 1910) y La acumulación del capital (Luxemburg 1913).

En la tercera sección analizamos la traducción práctica de estas posiciones a la política de la Social Democracia austríaca, considerando sus posiciones acerca del Estado austríaco y sus relaciones internacionales, la mayor agresividad imperialista del Imperio Austrohúngaro en esta época (con la anexión de Bosnia y Herzegovina en 1908), y la repercusión de los conflictos nacionales en el movimiento socialista. Si bien no existe una relación mecánica entre uno y otro aspecto, creemos que la posición frente al imperialismo de un teórico marxista debe ser juzgada en sus costados teórico y práctico, analizando las relaciones, concordancias y contradicciones entre ellos.

Intentamos demostrar que una concepción neo-armonicista de las crisis como un fenómeno cíclico que se corregía automáticamente favoreció una concepción del imperialismo como una política particular y contingente, que no era intrínsecamente necesaria para el desarrollo del capitalismo. En el terreno político, defendió el mantenimiento del status quo del Estado austríaco, una política que no se diferenció de la del resto de su partido sino tardíamente, y en aspectos parciales, ante la evolución del imperialismo austríaco y europeo.

\section{Primera Parte: Teoría de las crisis}

Sobre el trasfondo de un legado fragmentario de Marx sobre esta materia, los intelectuales de la Segunda Internacional formularon diversas teorías para explicar la naturaleza y las causas de las crisis económicas. Entre los antecedentes más importantes, podemos mencionar las obras de Luxemburg y Kaustky contra la teoría revisionista de Bernstein, que postulaba una tendencia a la desaparición de las crisis capitalistas (ver documentos en Tudor y Tudor 1988).

Otra obra influyente fue la del ruso Tugan-Baranowsky (1901), la primera en reparar en los esquemas de reproducción del Tomo II de El capital para explorar la posibilidad de la acumulación ampliada de capital a través de un proceso equilibrado. Tugan-Baranowsky llegó a la conclusión de que la capacidad de consumo de las masas populares no 
representaba un límite para la acumulación del capital. El capitalismo se puede expandir de manera ilimitada creando su propia demanda, garantizada por la inversión en el sector que produce medios de producción. Eso no quiere decir que no se produzcan desequilibrios: éstos ocurren constantemente debido a la anarquía de la producción, manifestándose como sobreproducción en algunas ramas que sobrepasa la demanda del resto de las ramas. Cuando este fenómeno se generaliza se produce una crisis, que es resuelta mediante una restauración del equilibrio. Así, si bien las crisis de desproporcionalidad son inherentes al sistema capitalista por su carácter anárquico, no encierran ningún límite estructural a su capacidad de expansión.

En respuesta a esta teoría Kautsky enfatizó el rol del subconsumo. Todas las crisis se manifiestan como sobreproducción, como un exceso de productos que no alcanza una demanda suficiente en el mercado. Pero la sobreproducción se trata de un concepto relativo: es una producción excesiva en relación con una demanda insuficiente.

Los capitalistas y los obreros a quienes éstos explotan constituyen un mercado que crece con el crecimiento de la riqueza de los capitalistas y del número de los trabajadores; pero ese mercado no crece con la misma rapidez que la acumulación del capital y la productividad del trabajo, y no es suficiente por sí solo para los medios de consumo creados por la gran industria capitalista (Kautsky 1902: 209).

La crisis y la depresión generada por la sobreproducción sólo puede resolverse colocando el excedente en un "mercado suplementario, fuera de su propio ámbito, entre los sectores profesionales y entre las naciones que no producen todavía según el modo capitalista" (Kautsky 1902: 209). Sin embargo, eventualmente ya no quedarán mercados suplementarios por conquistar y el capitalismo entrará en una fase de depresión: el límite de la demanda se impondrá de manera definitiva a su capacidad de expansión ${ }^{1}$.

El artículo de 1904 de Bauer se inscribe en este debate. Bauer empieza su exposición retomando la idea de Marx de que la forma dinero trae consigo la posibilidad de las crisis, al separar el momento en que un productor vende su mercancía y el momento en que usa el dinero obtenido para comprar otra mercancía, en otras palabras, al posibilitar un atesoramiento que deje a un grupo de productores sin la posibilidad de vender. Pero presentar esta posibilidad no es suficiente: es preciso demostrar cómo la producción específicamente capitalista convierte esa posibilidad en necesidad (Bauer 1904: 134-5).

Bauer intenta entonces construir un modelo del ciclo económico presuponiendo una economía capitalista "pura" (donde todos los miembros de la sociedad son capitalistas o

\footnotetext{
${ }^{1} \mathrm{Si}$ bien la tendencia a la depresión crónica es inherente al desarrollo capitalista, para Kaustky el proletariado habrá logrado superar este modo de producción antes de que éste alcance su límite absoluto. A su vez, esta no sería la última palabra de Kautsky sobre las crisis, ver por ejemplo Kautsky (1910).
} 
proletarios) y donde por el momento no existe el crédito. El centro de este modelo es el rol de la circulación del capital fijo (Bauer 1904: 135). Marx distingue el capital fijo del circulante en función de sus diferencias en el modo de rotación. El capital circulante, constituido por el capital variable y el capital constante destinado a materias primas, materias auxiliares, etc., rota completamente en un único ciclo: es decir, en un único ciclo desaparece enteramente como valor de uso, su valor se reproduce o se transfiere enteramente a las mercancías, retorna enteramente como dinero, y se emplea enteramente en la compra de nuevo capital circulante para iniciar el siguiente ciclo. El capital fijo, en cambio, está constituido por las maquinarias, edificios, etc., y rota completamente después de varios ciclos: su desgaste como valores de uso no se realiza enteramente en un único ciclo productivo, por lo que en cada ciclo su valor es transferido sólo parcialmente a las mercancías, retorna parcialmente como dinero, y (he aquí el punto que resalta Bauer) ese dinero es atesorado o inmovilizado durante varios ciclos, hasta el momento en que el capital fijo se desgasta completamente y es el momento de adquirir su reemplazo.

Este atesoramiento del dinero correspondiente al capital fijo que retorna en partes alícuotas es para Bauer el causante de las crisis, debido a que la producción capitalista no regula los tiempos de renovación del capital fijo. Podrían darse largos períodos en los que gran parte de las ramas de la producción no renueven su capital, produciéndose una crisis en el sector que produce medios de producción que se extendería pronto a toda la economía.

Supongamos que una gran parte del capital fijo de la sociedad fue renovada durante los últimos años. En consecuencia, actualmente la demanda de medios de producción disminuye, las industrias que los producen deben reducir su producción, y las ventas de las industrias que producen bienes de consumo en consecuencia también disminuirán: tenemos caídas de precios, ganancias y salarios, así como desempleo creciente en todo el sector industrial (Bauer 1904: 136).

Ahora bien, a esta fase de depresión le sucedería una de prosperidad. Pues llegará el momento en que el conjunto de los capitalistas debe renovar el capital fijo, poniendo en circulación el dinero que habían atesorado y creando un aumento de la demanda que trae consigo una fase ascendente para toda la economía. Tenemos entonces no simplemente una explicación de las crisis, sino un modelo del ciclo industrial, con su alternancia necesaria de fases de prosperidad y depresión (Bauer 1904: 136). A este modelo básico Bauer va añadiendo distintos fenómenos concomitantes.

En primer lugar, para Bauer en tiempos de prosperidad se produce un acortamiento del tiempo de rotación del capital ${ }^{2}$, por la reducción tanto del tiempo de circulación como de

\footnotetext{
${ }^{2}$ Marx define el tiempo de rotación como la suma de tiempo de producción y el tiempo de circulación. El tiempo de producción incluye el tiempo de trabajo propiamente dicho, así como las pausas del proceso de 
las pausas del proceso de producción. Bauer no explicita por qué, pero podemos suponer que se refiere al hecho de que la oferta encuentra inmediatamente su demanda, se reduce el tiempo en que los stocks son acumulados, hay más incentivos para producir de manera continua y sin pausas, la inversión mejora y acelera los medios de comunicación y transporte, etc. La reducción del tiempo de rotación "significa que el mismo capital rota con mayor frecuencia, que pone en movimiento a más trabajadores, y que, en consecuencia, produce más valor y -con una tasa de plusvalor invariable- una mayor masa de plusvalor que antes: es decir, significa un aumento de la tasa de ganancia" (Bauer 1904: $137)^{3}$.

Bauer añade otros fenómenos que caracterizan a la fase ascendente del ciclo y que contribuyen a la suba de la tasa de ganancia. Primero, la fase de prosperidad no sólo alienta la inversión del capital inmovilizado correspondiente al capital fijo, sino también la inversión del plusvalor obtenido en ciclos anteriores; es decir, la reproducción en escala ampliada. El mayor capital invertido aumenta el plusvalor producido en el nuevo ciclo, lo que para Bauer redunda en un aumento de la tasa de ganancia (Bauer 1904: 137). En nuestra opinión, éste no es un resultado directo, ya que la inversión del plusvalor representa un aumento del capital adelantado, por lo que el plusvalor producido a partir de esa inversión no se expresa inmediatamente como un aumento de la tasa de ganancia. El segundo fenómeno que sucede en la fase ascendente es un aumento de los precios más rápido que el aumento de los valores de los productos, y por tanto un aumento de la ganancia más rápido que el aumento del plusvalor total de la sociedad. Esto se debe a que la inversión del capital inmovilizado se expresa primeramente como una demanda de productos que supera la oferta disponible (oferta correspondiente a los tiempos de depresión, baja demanda y bajos precios), por lo que los precios ascienden por encima de sus valores (Bauer 1904: 138).

El crecimiento en precios y ganancias durante el período de prosperidad por tanto deviene de dos causas: por un lado, el hecho de que, a través del acortamiento del tiempo de rotación y el cambio en la proporción entre capital inmovilizado y capital invertido, el mismo capital pone en movimiento más trabajadores [y] extrae más plusvalor, y, por otro lado, el hecho de que, con la inversión productiva del capital hasta entonces inmovilizado, la ley del valor se afirma a sí misma a través de los valores actualmente creados añadiendo lo que se perdió durante el previo período de inmovilidad (Bauer 1904: 138).

producción. El tiempo de circulación está constituido por el tiempo de compra (lo que se tarda en adquirir los insumos) y el tiempo de venta (lo que se tarda en vender las mercancías producidas).

${ }^{3}$ El cálculo de la tasa de ganancia no se hace sobre cada ciclo del capital, sino por un período de tiempo dado, p. ej. un año. Así, si un capitalista, debido a una rotación más rápida, logra obtener en seis meses la misma ganancia que otro podría obtener en un año con el mismo capital adelantado, obtiene el doble de ganancia. 
Esta interpretación de la ley del valor es cuestionable. Bauer parece sugerir que la ley debe imponerse con exactitud matemática, de manera que si en una fase los precios se desviaron por encima de los valores, debe sobrevenir otra fase en la que eso se compense con precios desviados por debajo. La ley del valor efectivamente funciona como un ancla para los precios de mercado, conteniendo las desviaciones dentro de determinado margen, pero eso no significa que necesariamente deba compensar esas desviaciones a través de oscilaciones simétricas.

Bauer luego profundiza su análisis incorporando un estudio de la proporcionalidad entre los dos sectores de la producción: el Sector I, productor de medios de producción (es decir, capital constante, tanto fijo como circulante) y el Sector II, productor de bienes de consumo (es decir, capital variable, enteramente circulante). Esto se hace necesario porque si se caracteriza que la fase expansiva está impulsada por las ramas que producen capital fijo (pertenecientes al Sector I), es preciso analizar cómo se equilibra eso con el resto de los sectores.

La condición para el equilibrio en la reproducción capitalista en las etapas más avanzadas es (...) que la suma del capital constante consumido en la producción, la parte del plusvalor inmovilizada y la parte del plusvalor convertida en capital constante en las industrias que producen bienes de consumo deben ser igual a la suma del capital variable, la parte del plusvalor consumida como rédito capitalista y la parte del plusvalor convertida en capital variable en las industrias que producen medios de producción (Bauer 1904: 165).

Es decir, escrito como una ecuación: $c_{I I}+p i_{I I}+p c_{I I}=v_{I}+r_{I}+p v_{I}^{4}$. Bauer considera que el logro de este equilibrio resulta relativamente fácil en un período de prosperidad: todas las variables tienden a subir, y pueden hacerlo de manera equilibrada porque hay capital inmovilizado disponible para regular los desequilibrios moviéndose hacia uno u otro sector en función de los precios (Bauer 1904: 165).

No obstante, la prosperidad tiene límites definidos, que marcan la culminación de la fase ascendente y el inicio de la depresión. El tiempo de rotación del capital no puede ser acortado indefinidamente, pues su reducción alcanza límites técnicos. El capital inmovilizado eventualmente se acaba. La suba de la tasa de plusvalor también alcanza su límite, porque el mayor nivel de empleo fortalece a la clase trabajadora para contrarrestar el aumento del plusvalor absoluto y porque la suba generalizada de precios de las

\footnotetext{
${ }^{4}$ Hemos modificado la nomenclatura usada por Bauer: los subíndices $I$ y $I I$ se refieren al sector al que corresponde cada variable, $c$ es el capital constante, $v$ el capital variable, $r$ el rédito consumido por los capitalistas, $i$ el plusvalor inmovilizado, $p c$ el plusvalor invertido en capital constante y $p v$ el plusvalor invertido en capital variable.
} 
mercancías limita la extracción de plusvalor relativo ${ }^{5}$. Finalmente, la inversión desarrollada durante la fase de auge produce un aumento de la composición orgánica del capital, es decir, un crecimiento del capital constante en relación al capital variable, propio del progreso técnico. Esto genera la tendencia a la baja de la tasa de ganancia, que, al desaparecer todas las causas contrarrestantes propias de la fase ascendente del ciclo, termina predominando y marcando el fin de la prosperidad. Pero también genera una tendencia al desequilibrio, ya que si el capital constante crece a un mayor ritmo que el capital variable, la ecuación de equilibrio no puede mantenerse (Bauer 1904: 166-7).

De manera simétrica a la fase de prosperidad, la depresión se caracteriza por la inmovilización del capital en contraposición a la inversión productiva, el aumento del tiempo de rotación del capital y la caída de los precios y las ganancias.

Debido al aumento del plusvalor acumulado inmovilizado, la demanda de medios de producción cae; los grandes talleres, que surgieron durante el período de prosperidad, están ociosos; la disminución del rédito de capitalistas y trabajadores también deprime la demanda de bienes de consumo, que a la vez inhibe nuevas inversiones productivas en el Sector II y hace caer entonces la demanda de productos del Sector I; así desciende cada vez más fuerte la depresión sobre toda la industria (Bauer 1904: 167).

El movimiento descendente, a su vez, crea las condiciones para un nuevo período de prosperidad. La inversión decrece, por lo que el capital inmovilizado se acumula. El capital fijo incorporado durante la prosperidad se termina desgastando, demandando una nueva renovación. El desempleo debilita la posición de la clase trabajadora y permite aumentar la tasa de explotación o de plusvalor, lo cual, siendo constante la composición orgánica del capital (debido a la falta de inversión), redunda en un aumento de la tasa de ganancia.

Los bajos precios de los medios de producción facilitan las nuevas inversiones, y la baja tasa de ganancia hace parecer rentables emprendimientos que durante el período de prosperidad no habrían calificado como tales. Así surgen nuevas empresas, y con ellas nueva demanda en el mercado; finalmente, una demanda creciente de medios de producción se añade como resultado del uso y desgaste técnico y "moral" de los medios de producción creados durante el período de prosperidad. Así, el alza económica gradualmente empieza de nuevo (Bauer 1904: 168).

\footnotetext{
${ }^{5}$ El plusvalor absoluto es el que se obtiene extendiendo la jornada laboral, el relativo es que se obtiene por la reducción de los costos de vida de la clase trabajadora y por lo tanto del capital variable (lo que hace que en una misma jornada el trabajador pueda trabajar menos tiempo para reproducir sus condiciones de subsistencia y más tiempo para el capitalista).
} 
Sobre este modelo Bauer incorpora los efectos del sistema crediticio. A primera vista el crédito hace desaparecer el principal condicionante del ciclo, el capital inmovilizado: con el surgimiento de las instituciones financieras, los capitalistas ya no atesoran los retornos correspondientes al capital fijo esperando el momento de la renovación, sino que llevan ese dinero al banco a cambio de una tasa de interés; éste a su vez lo pone a valorizar productivamente en otras ramas de la producción (p. ej., otorgando créditos a otros capitalistas). Sin embargo, Bauer señala que en esos períodos en los que no hay renovación del capital fijo las entidades financieras receptan una enorme cantidad de capital que les resulta cada vez más difícil de poner a valorizar, lo que produce una baja en la tasa de interés. Por el contrario, en los momentos de renovación del capital fijo los capitalistas retiran los capitales depositados en los bancos (o solicitan créditos), produciendo una suba de la tasa de interés. Así, en tiempos de prosperidad la tasa de interés tiende a crecer. En un primer momento este crecimiento no supera a la tasa de ganancia, pero cuando ésta empieza a decrecer (con el agotamiento de la fase de prosperidad) es alcanzada por la tasa de interés. Éste es un nuevo límite encontrado por Bauer para la fase de prosperidad: en ese punto se vuelve más rentable valorizar el capital en las entidades financieras que seguir invirtiéndolo productivamente. Culmina entonces la fase de prosperidad, y se inicia una fase depresiva en los que los capitalistas retornan el capital que de otra manera tendrían inmovilizado a las entidades financieras, produciéndose una caída de la tasa de interés. En un determinado punto de esta caída las inversiones productivas empiezan a resultar claramente más lucrativas que depositar los capitales en el banco, con lo que se inicia la nueva fase de ascenso. La única diferencia que introduce el sistema crediticio entonces es acentuar y acelerar las fases del ciclo, ya que la tasa de interés se vuelve un indicador inmediato para el conjunto de los capitalistas de la rentabilidad del resto de las inversiones (Bauer 1904: 168-9).

Bauer concluye su artículo definiendo la teoría marxista de las crisis como "una teoría de la alternancia regular de la coyuntura económica en una sociedad puramente capitalista" (Bauer 1904: 169). Es decir, la teoría de las crisis es una teoría del ciclo económico: "Lo que Marx buscaba explicar, entonces, no es el momento dramático de la crisis, sino la sucesión regular de la prosperidad y la depresión" (Bauer 1904: 170). En segundo lugar, Bauer retoma las discusiones previas sobre las causas de la crisis, y en particular la discusión entre la teoría del subconsumo y la teoría de la desproporcionalidad de TuganBaranowsky.

la proporcionalidad de la producción (...) necesariamente será perturbada por el progreso hacia una mayor composición orgánica del capital, por el hecho de que una parte cada vez menor del capital sirve para la producción de bienes para consumo personal. La desproporcionalidad de la producción (...) aparece (...) en un momento de subconsumo. (Bauer 1904: 170). 
De esta manera, todos los factores identificados como causas de las crisis por los economistas (sobreproducción, acumulación, desproporcionalidad, inmovilización de capital, subconsumo, etc.) reaparecen en la teoría de Marx "como los eslabones sucesivos de una cadena lógica" (Bauer 1904: 170).

Ahora bien, a diferencia de Kautsky, no hay ningún indicio en la exposición de Bauer del desarrollo de una tendencia depresiva crónica o de un límite absoluto para la expansión capitalista. En ese sentido, el espíritu de su posición es más afín a la concepción de las crisis de Tugan-Baranowsky. Esta posición ha sido caracterizada como "neo-armonicista" por Rosdolsky (2004: 497); lo que se ajusta en nuestra opinión tanto a la tesis general como a inconsistencias secundarias del modelo que hemos destacado (en primer lugar, la idea de que reinvertir plusvalor acumulado aumenta de por sí la tasa de ganancia, y en segundo lugar, la idea de que la ley del valor se manifiesta a través de oscilaciones simétricas de los precios), que abonan a la idea de una tendencia inmanente al equilibrio de la acumulación capitalista, donde la crisis es sólo un momento particular del ciclo.

\section{Segunda parte: Teoría del imperialismo}

\section{El principio de las nacionalidades en la Social Democracia austríaca}

Un autor ha descrito de la siguiente forma la situación de las nacionalidades en Austria a fines del siglo XIX:

Los cambios sociales y económicos de la segunda mitad del siglo XIX tendieron a ensanchar la brecha entre las naciones de Austria. Gradualmente, una clase media había emergido entre las naciones no alemanas de Austria, desafiando la hegemonía alemana en el Estado (...) los conflictos nacionales se luchaban en los concejos de ciudad y las dietas provinciales, así como en el parlamento central, y frecuentemente las disputas se acompañaban de revueltas y violencia callejera. Dado que las naciones luchaban ante todo por posiciones en la administración, la cuestión de cuál debía ser el lenguaje oficial asumió una importancia difícilmente entendible para el mundo exterior (Kogan 1949: 204-5).

Debido a particularidades del parlamento austríaco, donde una pequeña minoría de parlamentarios podía obstruir el funcionamiento de todo el parlamento recurriendo a mociones de orden, los distintos grupos nacionales usaron este arma de acuerdo a sus intereses, paralizando el parlamento y empujando al Ejecutivo imperial a gobernar por decreto (Kogan 1949: 205).

La Social Democracia de la mitad occidental del Imperio se vio obligada a abordar estos problemas nacionales. En 1897, el partido austríaco fue reorganizado como un partido federal, dando autonomía a los partidos de las distintas nacionalidades, unidos por un 
liderazgo y un Congreso Pan-Austríaco que se suponía debía reunirse cada dos años, a la vez que cada partido mantenía sus propios líderes y congresos (Kogan 1949: 206). Entre estos partidos, el austro-alemán y el checo eran los más importantes y numerosos, con pequeños partidos representando a los polacos, italianos, rutenios, y eslavos del sur.

En 1899 la Social Democracia austríaca aprobó un programa que abordaba específicamente con la cuestión nacional, llamado Programa de Brno. Éste planteaba que la solución de los conflictos nacionales de Austria vendría de la constitución de una "federación democrática de nacionalidades", dividida en áreas nacionales autónomas a cargo de sus propios asuntos linguiísticos y culturales, con protección a las minorías. Después de un debate, el programa no se pronunció a favor de ningún lenguaje en particular como lengua común del Imperio (Kogan 1949: 208). Este programa debe ser interpretado como un principio territorial de solución al problema nacional, que sería la política oficial del partido pan-austríaco hasta su disolución.

Sólo un delegado planteó un punto de vista diferente: el delegado Kristan de Trieste, representando a los eslavos del sur. En su opinión, la solución de distritos delimitados étnicamente no resolvería el problema de las minorías, más aún teniendo en cuenta los permanentes movimientos de población. En su opinión, la igualdad de derechos tenía que provenir de la organización de las naciones no como una entidad territorial sino como la suma de individuos que se reconocen de tal nación (Kogan 1949: 209). El delegado no especificó demasiado su propuesta, pero sería la primera aparición de un punto de vista que sería retomado años más tarde por varios Austro-Marxistas, incluyendo a Otto Bauer.

\section{El desarrollo del principio no territorial de las nacionalidades}

El principio no territorial, o personal, para la solución a la cuestión nacional fue desarrollado por primera vez por el Austro-marxista Karl Renner (1902), que abogaba por una amplia reorganización del Imperio a través de la autonomía cultural nacional puesta en práctica mediante un doble sistema federal de autoridades: uno extraterritorial, elegido por los miembros de cada nacionalidad, con la tarea de ocuparse de sus asuntos culturales, y otro sistema de gobierno político y económico, dividido territorialmente.

Esta idea de Renner no modificaría la política oficial del partido, pero sería retomada por Bauer en un contexto particular: A partir de 1905 los escritos sobre la cuestión nacional, titulados a menudo con variantes de "La Social Democracia y la cuestión nacional", se multiplican (Haupt y Löwy 1980: 59-60). En Austria este interés tiene como trasfondo los periódicos conflictos nacionales, que en este momento repercuten con fuerza al interior del Partido. Ese año la unidad de los socialistas austro-alemanes y checos fue significativamente amenazada por un conflicto en el que la Comisión Sindical Checa demandó su paridad con la Comisión Sindical Austríaca y el derecho exclusivo de 
organizar a los trabajadores checos. Esta demanda fue derrotada en el Congreso Sindical Internacional y en un Congreso Sindical Austríaco, en diciembre de 1905. La división no se extendió en gran medida por el efecto unificador de la lucha por el sufragio universal que los socialistas estaban librando en ese momento (Knapp 1980: 139-140).

En este contexto de interés político por la cuestión nacional, Bauer, en su obra más famosa (Bauer 1907), abordó este problema con un carácter más general: una teoría marxista de la nación, que sirviera de justificación a una propuesta política basada en la autonomía nacional cultural. Formuló una definición de la nacionalidad como una comunidad de carácter que emerge de una comunidad de destino. Si bien la expresión suena idealista, su idea es que el conjunto de características comunes de una nacionalidad emerge de una historia común que puede ser reconstruida de manera materialista (enlazando las dimensiones económicas, sociales y culturales), y que no es una esencia ni espiritual ni biológica permanente: "el respectivo carácter nacional no es sino un precipitado de procesos históricos pasados que será ulteriormente alterado por procesos históricos subsiguientes" (Bauer 1907: 10).

$\mathrm{Su}$ tesis histórica general es que la nación moderna surge de un proceso de integración social producto del desarrollo económico (en particular, la unificación por medio del mercado de distintas esferas productivas locales), que genera una cultura nacional pasible de ser asimilada parcialmente más allá de las clases privilegiadas. Para las "naciones sin historia", que durante el período de construcción de las grandes naciones (s. XIX) no constituyeron una clase dominante propia sino que estuvieron bajo el dominio de otra nacionalidad (Bauer 1907: 176), esta integración a la nación de las masas populares propia del capitalismo moderno constituyó la base de su despertar nacional.

Esta tendencia histórica es analizada concretamente en el libro a través del caso específico de Austria ${ }^{6}$. La propuesta de Bauer para resolver las tensiones nacionales era la "autonomía cultural nacional", que implicaba la constitución de corporaciones autónomas por nación, no localizadas territorialmente, que se encargaran de administrar la vida cultural de dicha nación, principalmente el derecho a la educación primaria en su idioma y a tener instituciones culturales propias (Bauer 1907: 259-309).

Este análisis fue su punto de partida para analizar "la transformación del principio de nacionalidad en su época", es decir, el análisis del imperialismo o expansionismo capitalista. Bauer considera que durante el siglo XIX la gran transformación del sistema de estados se desarrolló sobre la base del "principio de nacionalidad": cada nación tiene su estado, cada estado comprende una sola nación. Esto se transformó en la época del imperialismo.

\section{El expansionismo capitalista}

\footnotetext{
${ }^{6}$ La mitad húngara del Imperio tenía un partido separado al austríaco; las propuestas de reorganización estatal de la Social Democracia austríaca se aplicaban a la mitad occidental del Imperio.
} 
Bauer comienza su presentación del expansionismo capitalista analizando su base económica, retomando sus planteos sobre la importancia de la movilización de capital y del acortamiento de su tiempo de circulación para el despegue de la acumulación.

(...) sólo ahora estamos en posición de entender los objetivos de la política económica capitalista. Busca adquirir esferas de inversión para capital y mercado para sus productos. Podemos ahora ver que estos no son objetivos separados, sino de hecho son un mismo objetivo. Si abro una esfera de inversión al capital improductivo, tentándolo hacia la esfera de la producción con la perspectiva de ganancias adicionales, provoco ventas de mercancías (...) E inversamente, si abro un nuevo mercado para bienes, el tiempo de retorno del capital se acorta, las ganancias aumentan, una demanda adicional emerge para el capital disponible, y el capital improductivo se desplaza hacia la esfera de la producción (Bauer 1907: 372).

De esta manera, para Bauer cualquier nuevo mercado/esfera de inversión, sea doméstico o en una colonia, permite garantizar el movimiento y el empleo productivo del capital. Veremos que las tarifas proteccionistas fomentan la exportación de mercancías, mientras que el diferencial de tasa de ganancia hace lo suyo con la exportación de capital, todo lo cual redunda en una mayor actividad económica en la metrópoli (Bauer 1907: 376-7). Para las teorías posteriores del imperialismo estos métodos no serán indistintos: para Hilferding el imperialismo será una consecuencia de la necesidad de exportar capitales, mientras que para Luxemburg lo será de la necesidad de mercados adicionales. Veremos qué consecuencia tiene esto más adelante.

Bauer luego explica el rol de los aranceles para acortar el tiempo de inactividad del capital. En su opinión, el objetivo último de las tarifas aduaneras es "estructurar mejor la relación entre capital productivo e improductivo, entre el tiempo de producción y el tiempo de circulación del capital" (Bauer 1907: 373). Retomando un planteo de Hilferding, Bauer añade que en su época se transforma la función predominante de las tarifas aduaneras, que se constituyen principalmente como un arma para los cárteles y trusts. Con sus peculiaridades, ambos tipos de entidades tienen la capacidad de controlar el mercado y la fijación de los precios en su país, por su naturaleza monopólica y por estar protegidos por los aranceles. Sin embargo, no pueden subir indefinidamente el precio de los productos: eso implicaría una disminución de la demanda (a un determinado nivel de precios, los consumidores ya no comprarían) que debería ser equiparada con una disminución de la producción, lo que produciría un aumento del costo por unidad de producto (debido a los costos fijos de instalaciones y maquinaria). Este problema se resuelve vendiendo en el extranjero a un precio más bajo, lo que permite elevar el precio de venta en el mercado doméstico y a la vez mantener bajo el costo por unidad de producto (ya que al exportar parte de la producción ésta no se ve reducida), aumentando las ganancias en el mercado doméstico. Así, la práctica del dumping es una herramienta necesaria en la política de precios de los cárteles. Esto es "útil para la economía como un todo" desde el punto de 
vista de la relación entre capital improductivo y capital invertido productivamente, ya que mantiene a niveles elevados la producción, la demanda y el empleo en el mercado doméstico (Bauer 1907: 373-375).

La política expansionista tiene otro objetivo más. Dado que la tasa de ganancia en los países menos desarrollados es inicialmente más alta que en Europa, se vuelve más rentable para el capital garantizarse esferas de inversión en dichos países, que se vuelven receptores no sólo de mercancías, sino también de capital. Como corolario, "sumas más grandes de plusvalor pasan desde allí hacia el capital europeo que lo que éste podría haberse apropiado si hubiera invertido dentro de su propio país en Europa" (Bauer 1907: 377), por lo que en este caso el imperialismo también parece servir a la totalidad de la población de los países colonizadores.

Estas tendencias producen una competencia entre los países imperialistas por el reparto del mercado mundial y de esferas de inversión, para lo cual se emplean todos los instrumentos del poder estatal, especialmente la fuerza militar.

El imperialismo moderno no quiere formar una zona económica unificada que incluya todos los países, sino más bien encerrar la zona económica del país individual dentro de una frontera aduanera. Abre los países menos desarrollados y se asegura esferas de inversión y áreas de venta allí para los capitalistas de su propio país, excluyendo a los capitalistas de otros países. No sueña con la libertad, sino que se prepara para la guerra. (Bauer 1907: 379)

Hasta este punto de la exposición el imperialismo aparece como un fenómeno progresivo, tan beneficioso para la clase trabajadora como lo es para la burguesía. Los problemas que representa para la clase trabajadora surgen al considerar nuevos factores. El expansionismo capitalista no sólo reduce el período de retorno del capital, sino que altera su distribución entre las ramas de producción y por lo tanto entre las clases. En primer lugar, la protección aduanera y las prácticas monopólicas reducen la productividad del trabajo y aumentan el precio de las mercancías, por lo que disminuye el poder de compra de los salarios. No obstante, los salarios también tienden a aumentar por la aceleración del flujo de capital y el aumento de la demanda de fuerza de trabajo. En segundo lugar, las tarifas tienden a arrastrar una porción mayor del capital hacia las ramas con mayor composición orgánica, que tienen una menor capacidad para incorporar trabajo. En tercer lugar, las prácticas de exportación de los cárteles dañan a las empresas con menor composición orgánica del capital que incorporan más trabajo. Por ejemplo, los cárteles de acero alemanes venden más barato en Inglaterra que en su mercado doméstico, reduciendo la capacidad competitiva de la industria dedicada al procesamiento del hierro en Alemania. Es notable cómo en este punto Bauer considera el interés de la clase trabajadora desde un marco estrechamente nacional. En quinto lugar, las ramas económicas monopólicas y de mayor 
concentración son las que peores condiciones ofrecen para la lucha sindical. En sexto lugar, las inmensas sumas destinadas a desarrollar el poder militar y naval de las potencias europeas hacen descender la tasa social de acumulación por la enorme inversión en sectores improductivos, cuyo costo es mayormente pagado por la clase trabajadora a través de impuestos indirectos (Bauer 1907: 382-383). Finalmente:

La exportación de capital trae una reducción en la demanda del mercado de trabajo europeo. Puede ser que el capital que va hacia las regiones extranjeras habría permanecido temporalmente improductivo si esta salida no hubiese sido provista. Mas ningún capital permanece permanentemente improductivo; este capital exportado hubiera en última instancia encontrado su vía hacia la esfera de la producción en casa (Bauer 1907: 385).

Es decir, los límites a la inversión que pueden existir en un mercado doméstico son para él transitorios y prácticamente irrelevantes. Como señalamos anteriormente, Bauer no considera que haya una necesidad intrínseca de conquista de mercados o esferas de inversión, pues de su teoría del ciclo se sigue que tarde o temprano éstos aparecen en la esfera doméstica. Volveremos sobre este punto cuando analicemos su recepción de la obra de Hilferding. Su conclusión es la siguiente:

Es todo esto lo que determina la posición de la clase obrera en torno al imperialismo. $\mathrm{Su}$ visión del imperialismo es en todos lados una visión sobria. Calcula en cada caso individual si los efectos beneficiosos del imperialismo valen realmente el sacrificio. Su circunspección se transforma en desconfianza, dado que ve que es difícil en cada caso individual calcular por anticipado la fuerza que será ejercida por la serie individual de efectos que emergen del desarrollo de nuevos mercados y esferas de inversión (Bauer 1907: 389-390).

Como vemos, su condena del imperialismo en términos económicos no es demasiado firme, y otorga muchas concesiones a la idea de sus posibles (aunque parciales) ventajas económicas. Luego plantea: "La desconfianza sentida por la clase obrera hacia el imperialismo se intensifica hasta el punto de hostilidad consciente apenas considera los efectos políticos y culturales generales del imperialismo", mencionando temas comunes de la crítica socialista de la época, tales como la limitación del parlamentarismo, la difusión del racismo, etc. (Bauer 1907: 390).

En torno a las consecuencias del imperialismo sobre la realidad de Austria-Hungría, al constatar el crecimiento de las tensiones entre nacionalidades y la posibilidad de que los imperialismos extranjeros las utilizaran para sus propios fines planteó: 
Si Austria se desintegra en la época de la sociedad capitalista, no será desgarrada por el viejo principio liberal de nacionalidad. Más bien, se desintegrará únicamente si el expansionismo capitalista es capaz de lograr que la voluntad nacional sirva a su causa. El colapso de Austria presupone el triunfo del imperialismo en el Imperio Alemán, en Rusia, en Italia. Pero el triunfo del imperialismo significará también la derrota de la clase trabajadora en esos países (Bauer 1907: 403).

La conclusión parece ser ni más ni menos que la supervivencia del Estado imperial y monárquico de Austria-Hungría ¡es un bien para la clase trabajadora de todos los países!

\section{El capital financiero}

En 1910 Rudolf Hilferding publicó El capital financiero, que tuvo una gran influencia sobre los debates acerca del imperialismo. Al ofrecer un análisis riguroso y novedoso de las características del capitalismo del momento y refutar algunas tesis centrales de los revisionistas (como la idea de que la concentración del capital tendía a eliminar las crisis), el libro fue recibido favorablemente por teóricos asimilables al Centro de la Social Democracia como Bauer (1910) así como de la Izquierda, tal como Julian Marchwleski, conocido como Karski (1910), un compañero cercano de Rosa Luxemburg. Bauer planteó que por su lenguaje y su forma de presentación "la obra de Hilferding se lee casi como un volumen adicional de El capital. Y aún así, con esos medios, ha dominado los fenómenos económicos más nuevos: hechos que eran totalmente desconocidos para Marx" (Bauer 1910b: 416).

En la reseña Bauer se limita presentar las tesis principales de Hilferding y expresar su adhesión. El grueso de la reseña se centra en el análisis de las tres primeras partes del libro: la teoría del dinero y el crédito, la caracterización de las sociedades por acciones y el capital ficticio, y el análisis del capital financiero y el monopolio (Bauer 1910b: 416-21). A las dos últimas partes, que son las más relevantes para nuestro trabajo, ya que abordan la teoría de las crisis y el imperialismo, Bauer dedica sólo dos párrafos.

En lo que respecta a la teoría de las crisis, Bauer comienza diciendo: "En contraste con las presentaciones previas de la teoría marxista de las crisis, incluyendo la mía, Hilferding provee evidencia convincente de que 'la pura acumulación de dinero a nivel de la sociedad como un todo es imposible bajo el supuesto de una producción reducida o estancada" (Bauer 1910b: 421-2). En el prefacio a la segunda edición de La cuestión de las nacionalidades, de 1924, Bauer expresará de esta forma esta autocrítica: "bajo la influencia de la obra de Tugan-Baranowski, sobreestimé el efecto de la extracción de capital dinerario liberado del proceso de circulación; este error ha sido corregido desde entonces por Rudolf Hilferding en El capital financiero" (Bauer 1907: 6). El planteo de Hilferding 
(simplificado) es que cuando la tasa de ganancia desciende debido al aumento de la composición orgánica del capital el capitalista deja de invertir, lo cual redunda en una sobreproducción de medios de producción y bienes de consumo que puede convertirse en estancamiento económico generalizado (Hilferding 1910: 380). En tal situación un capitalista no tiene ningún motivo para ampliar la producción, aunque disponga de grandes tesoros de dinero. En lo que respecta al imperialismo, Bauer plantea:

El trabajo cierra con una presentación de la política económica moderna. Lo que es original aquí, sobre todo, es la presentación teórica de las exportaciones de capital. Por contraste, en la discusión de los cambios en la política comercial, en la estructura de clases y la lucha de clases, en el conflicto sindical y en la crítica del imperialismo Hilferding sigue de cerca mucho de lo que ya ha sido explicado por otros, especialmente por Kautsky, Parvus, Cunow e incluso por Hilferding mismo en Neue Zeit, así como por mí en La cuestión de las nacionalidades. Mas esos capítulos son también muy importantes porque son los más populares de todo el libro, y su argumentación será un arma efectiva para nosotros en la lucha contra las ilusiones democráticas, libremercadistas y revisionistas (Bauer 1910b: 422).

Lo que Bauer llama al pasar el aspecto más original del trabajo (la teoría de la exportación de capitales, que no desarrolla) es precisamente lo que refuta uno de sus planteos previos. En La cuestión de las nacionalidades Bauer no consideraba que la expansión capitalista fuera algo necesario (es decir inevitable), puesto que el capital estacionado eventualmente regresaría a la actividad productiva. Para Hilferding, en cambio, la cartelización protegida por tarifas aduaneras generaba límites objetivos a la magnitud de capital que podía ser invertida en el país de origen, creando para los capitalistas la necesidad de exportar capital:

...los cárteles significan un retardo de la inversión de capital. En las industrias cartelizadas, porque la primera medida del cartel es la limitación de la producción; en las no cartelizadas, porque la reducción de la tasa de ganancia atemoriza a los inversores de capital. Así crece rápidamente, por un lado, la masa del capital determinado para la inversión, mientras que, por otro, se contrae su posibilidad de inversión. Esta contradicción exige su solución, y la encuentra en la exportación de capital. (Hilferding 1910: 348-9).

Al estar el resto de las zonas del mundo protegidas por tarifas aduaneras, la exportación de capital significa la apropiación de territorio para cercarlo, generando la lucha por el mercado mundial y el enfrentamiento entre las potencias. Es por esto que no son indistintas (como se sugiere en La cuestión de las nacionalidades) la exportación de mercancías y la de capitales, siendo esta última la que domina la dinámica del imperialismo. La falta de 
asimilación de estos conceptos por parte de Bauer y la pervivencia de sus viejas ideas se hará evidente en su recepción de la obra de Rosa Luxemburg, La acumulación de capital.

\section{La recepción de La acumulación de capital: una teoría demográfica del ciclo industrial}

A la publicación del trabajo de Rosa Luxemburg (1913) Bauer respondió con una extensa reseña en la revista teórica de la Social Democracia alemana, Die Neue Zeit (Bauer 1913). Bauer resumió de esta manera el argumento de Luxemburg:

Rosa Luxemburg se basa en la vieja hipótesis de las "terceras personas" [dritten Personen]. Ella cree que la parte del plusvalor que ha de ser acumulada no puede ser realizada a menos que la producción capitalista pueda vender sus valores excedentes fuera de su propia esfera, a los productores pequeño-burgueses y pequeños campesinos no capitalistas. Esto explica la presión del capital por la extensión de sus mercados. De allí el esfuerzo por destruir la economía natural, por transformar la producción mercantil simple en todos lados en producción capitalista, por hacer de la totalidad del planeta un área de mercado para la industria capitalista: ¡de ahí el imperialismo! Pero una vez que el área del mercado no puede ya ser expandida, el capitalismo no puede vender una gran parte de sus mercancías. Se sofoca en la riqueza que ha creado. Su última hora se acerca. (Bauer 1913a: 723).

Bauer le reconoce a Luxemburg que es posible una resolución algebraica y formal del problema de quién compra la parte acumulada del plusvalor en términos de los esquemas de reproducción al estilo de Tugan-Baranowski, pero que esta solución, debido a sus supuestos, no se condice con las condiciones reales de la producción. Para Bauer, no obstante, la razón de esto es distinta: hay una condición de equilibrio extrínseca a los esquemas de reproducción, que es la relación entre la acumulación de capital (primariamente la ampliación del capital variable) y el crecimiento demográfico. Todas las sociedades, incluso las pre-capitalistas, necesitan expandir la producción para poder satisfacer la demanda creciente de una población en expansión. En el caso del capitalismo esto se hace a través del proceso de acumulación de capital.

Los capitalistas llevan a cabo esta acumulación para aumentar su ganancia; pero la consecuencia social de la acumulación es proveer los bienes de consumo requeridos por el aumento de la población. [...] Ahora deseamos descubrir [...] cómo la acumulación de capital debe tener lugar de manera que pueda permanecer en equilibrio con el crecimiento poblacional (Bauer 1913a: 724). 
Para ello Bauer presenta de manera sucesiva los esquemas de reproducción de una sociedad capitalista por un período de cuatro años, partiendo de determinados supuestos; en particular, una tasa de plusvalor fija, una tasa fija de acumulación para el capital variable igual a una tasa fija de crecimiento poblacional, y una tasa fija de acumulación para el capital constante superior a la del capital variable (para que se verifique el incremento de la composición orgánica del capital). Bauer considera que de esta manera corrige algunas arbitrariedades de los esquemas de Marx (Bauer 1913a: 728). Desde un punto de vista matemático Bauer deriva efectivamente de estos supuestos una reproducción en escala ampliada equilibrada, donde la principal particularidad es que, para mantener el equilibrio, parte del plusvalor producido en el sector II debe ser invertido en el sector I. Esta reproducción se da sin requerir que las mercancías en las cuales está contenida la parte acumulada del plusvalor se realicen a través de la venta a "terceras personas". De hecho, contra la explicación de Luxemburg, Bauer formula la siguiente objeción:

¿Qué tipo de mercancías son éstas? Son precisamente los medios de producción que los capitalistas necesitan para expandir su capacidad productiva, y los medios de consumo que requieren para mantener la creciente fuerza de trabajo. Si estos productos fueran expulsados del mundo capitalista, la producción en escala ampliada en el año siguiente sería del todo imposible (Bauer 1913a: 736).

Luego de exponer este modelo de acumulación equilibrada, Bauer analiza la relación entre la acumulación de capital variable y el crecimiento poblacional. De acuerdo con su teoría, el crecimiento de la población es la variable independiente a la cual la tasa de acumulación debe adaptarse, y las crisis periódicas ocurren ya sea porque la tasa de acumulación excede el crecimiento de la población o porque se queda atrás del mismo. Bajo el capitalismo los ajustes de la producción se realizan espontáneamente, impulsados por la persecución de beneficios individuales por parte de capitalistas individuales, de forma tal que cualquier equilibrio entre crecimiento de la población y acumulación es inestable.

A veces habrá subacumulación: el capital variable (invertido en salarios) crecerá más lento que la población, generando desempleo y la emergencia de un ejército industrial de reserva. Eso producirá una caída de los salarios que se corresponderá con un aumento del plusvalor relativo obtenido por los capitalistas, y por lo tanto de la tasa de plusvalor. Bauer considera que esto constituye un mecanismo de regulación automático, ya que tendría como efecto la restauración del equilibrio. Para sostener esto acuña el concepto de tasa social de acumulación, que define como la relación entre el plusvalor acumulado y el plusvalor total más el capital variable: "Bajo la presión del ejército industrial de reserva la tasa de plusvalor aumenta y con ella la tasa de acumulación social, hasta que esta última se vuelva lo suficientemente grande para que el capital variable crezca a la misma tasa que 
la fuerza de trabajo, pese a la creciente composición orgánica" (Bauer 1913a: 738, énfasis nuestro). A nuestro entender esta relación es errónea, ya que las variaciones del plusvalor relativo no afectan la suma del plusvalor total más el capital variable, sino su distribución, por lo que se mantiene invariable la tasa de acumulación social según fue definida por Bauer.

El crecimiento de la tasa de acumulación llega hasta el punto en que supera la tasa de crecimiento poblacional, produciéndose sobreacumulación. Se reduce el desempleo, aumentan los salarios y caen las ganancias, precipitándose la crisis como forma de restaurar las relaciones cuantitativas necesarias entre acumulación y crecimiento demográfico: "Si la tasa de acumulación es demasiado grande, el ejército de reserva es rápidamente absorbido, los salarios suben, la tasa de plusvalor cae, y con ella la tasa de acumulación social, desacelerando entonces una vez más el crecimiento del capital variable y logrando el ajuste de la acumulación al crecimiento poblacional" (Bauer 1913a: 739).

Podemos decir entonces que Bauer formula una teoría demográfica de los ciclos económicos:

La alternancia periódica de prosperidad, crisis y depresión es la expresión empírica del hecho de que el mecanismo del modo de producción capitalista automáticamente genera sobreacumulación y subacumulación, con la acumulación de capital ajustándose una y otra vez al crecimiento de la población (Bauer 1913a: 740).

Al volverse al final de su artículo a la explicación del imperialismo de Luxemburg, Bauer concede que "un núcleo de verdad se esconde en la falsa explicación. Mientras que la acumulación en una economía capitalista aislada no es imposible, está sin embargo confinada dentro de ciertos límites. El imperialismo sirve en efecto para ampliar esos límites" (Bauer 1913a: 742). La destrucción de los viejos modos de producción en las colonias permite aplazar el límite que representa el crecimiento de la fuerza de trabajo en la metrópoli ya que su consecuencia es la incorporación de grandes masas de trabajadores a la producción capitalista, ya sea por los desplazamientos y migraciones hacia las áreas capitalistas o por la exportación de capital a las colonias. Bauer luego postula que el nivel de acumulación también depende de un aumento de la composición orgánica del capital; el imperialismo jugaría en este sentido también un rol favorable al estimular el desarrollo de las ramas de capital con mayor composición orgánica y proveer materias primas del extranjero. Finalmente, al ser las colonias también un lugar de colocación de mercancías, el imperialismo genera una contra-tendencia a la sobreproducción garantizando un mercado de reserva: "Si el imperialismo no es un medio para hacer posible la acumulación en primer lugar, es no obstante un medio para estirar sus límites y facilitar la superación de las crisis que resultan periódicamente de la sobreacumulación. Este esfuerzo es de hecho una raíz del imperialismo, aunque no la única” (Bauer 1913a: 109). 
Bauer se previene que su teoría pueda ser interpretada como una apología del capitalismo, ya que encuentra en el crecimiento demográfico un límite objetivo a la acumulación y demuestra la necesidad de las crisis como mecanismo de regulación. Sin embargo, este límite es en cierto modo extrínseco a la producción capitalista, representando una suerte de barrera natural, sin ninguna barrera social que se le contraponga. Si el capitalismo es concebible por tanto sin expansión, la misma contribuye a atenuar y acortar las crisis: "Si su expansión es evitada, el límite a la acumulación se estrecha y las crisis se vuelven más frecuentes, más largas, más devastadoras" (Bauer 1913a: 109). Concluye:

El capitalismo no colapsará por la imposibilidad mecánica de realizar el plusvalor. Sucumbirá a la indignación que genera en las masas. El capitalismo no colapsará cuando el último campesino y pequeño burgués en el mundo entero se conviertan en obreros asalariados, de tal forma que no quede ningún mercado adicional abierto al capitalismo. Será eliminado mucho antes, por la creciente 'indignación de la clase obrera, una clase cuyo número aumenta de manera constante y que es disciplinada, educada, unida y organizada por el mecanismo mismo del proceso capitalista de producción' (Bauer 1913a: 743, entre comillas cita de Marx del Tomo I de El Capital).

Si bien esta presentación de la teoría del ciclo incorpora el límite demográfico como un elemento novedoso, consideramos que tiene el mismo carácter neo-armonicista que su teoría anterior. Su nuevo modelo es defectuoso e inconsistente en varios sentidos. En particular, el supuesto de una composición orgánica creciente implica un aumento constante de la productividad, lo que tiene dos consecuencias. Primero, disminuye la el valor de la fuerza de trabajo y crece el plusvalor relativo, lo cual es inconsistente con el otro supuesto de una tasa de plusvalor constante. Segundo, la mayor productividad implica un aumento de la cantidad de valores de uso representada en el mismo capital variable, lo que podría posibilitar que el mismo capital variable alcance para emplear a una población creciente, por lo cual carece de fundamento el supuesto de que la tasa de acumulación de capital variable debe ser idéntica al crecimiento de la población. Por otra parte, Grossman demostró que extendiendo el modelo durante algunas décadas (Bauer presenta sólo los primeros cuatro años) éste termina colapsando, ya que en un determinado momento para seguir acumulando a las tasas fijadas por Bauer se requiere una cantidad de plusvalor superior a la que ha sido efectivamente producida (Grossmann 1929: 80-85). Otro problema del modelo es que supone que la fase de ascenso necesariamente absorbe el ejército de reserva, cuando según Marx en realidad puede convivir con altos niveles de desocupación ${ }^{7}$. Conceptualmente es problemática la idea de que las crisis surgen sólo por

\footnotetext{
7 “No constituye una contradicción el que esta sobreproducción de capital esté acompañada por una sobrepoblación relativa más o menos grande. Las mismas circunstancias que han elevado la fuerza productiva del trabajo, aumentado la masa de los productos mercantiles, expandido los mercados, acelerado la
} 
un límite "externo" a la producción capitalista, representado por el crecimiento poblacional, así como la idea de que los niveles de acumulación pueden ajustarse automáticamente a ese límite. Finalmente, al igual que en su análisis de 1907, el imperialismo no aparece como una consecuencia necesaria de los límites de la acumulación de capital, sino como una solución o atenuación posible de sus obstáculos coyunturales, lo cual demuestra su asimilación superficial de la explicación de Hilferding de la exportación de capital.

\section{Tercera parte: Bauer frente a la política austríaca}

\section{La situación de Austria en el reparto del mundo}

Bauer intentó interpretar con mayor detalle la influencia de la etapa imperialista en Austria.Su planteo en un artículo de 1908 fue que el lugar de Austria debía ser interpretado a la luz del principal enfrentamiento interimperialista del momento: la oposición entre Alemania y Gran Bretaña. A la luz de este enfrentamiento interpretaba la crisis diplomática producida entre Austria y Rusia en ese año por el anuncio de Austria de la construcción de un ferrocarril entre Bosnia y Mitrovitsa (actualmente en Kosovo). Para Bauer los potenciales beneficios económicos de este proyecto eran insignificantes en relación a sus grandes desventajas al aumentar la tensión internacional y dar la impresión de que Austria perseguía una política de conquista. El apoyo de Inglaterra a Rusia debía interpretarse como un golpe indirecto al imperialismo alemán a través de Austria (Bauer 1908: 377).

Sobre la asociación austro-alemana su propia recomendación era la siguiente:

La alianza con Alemania, habiendo adquirido ahora un nuevo contenido, ciertamente no es una alianza que los pueblos de Austria quieran disolver en este momento. Necesitamos el apoyo de Alemania porque el zarismo se está fortaleciendo nuevamente; de otra manera seríamos reducidos a una alarmante relación de dependencia con el genocida reino zarista (...) Pero, si no podemos disolver nuestra alianza con Alemania e Italia, lo mismo tenemos razones para estar insatisfechos con su desarrollo interno (Bauer 1908: 378).

A su vez, planteaba la importancia de rechazar un involucramiento colonial de Austria, cuya solución sería

Una constitución democrática dando representación a la mayoría de la población en una asamblea legislativa llevaría toda la atención del país a su gran problema social la introducción de derechos de propiedad burgueses para los campesinos- y le quitaría al movimiento Gran Serbio cualquier apoyo (Bauer 1908:379).

acumulación del capital, tanto respecto a su masa como a su valor, y rebajado la tasa de ganancia, las mismas circunstancias han generado una sobrepoblación relativa y la generan constantemente" (Marx 1894: 328-329) 
Su rechazo al movimiento Gran Serbio (que buscaba una unidad de los pueblos balcánicos bajo la égida del Estado serbio) se originaba en su idea de que los eslavos de Austria debían mantenerse dentro del Estado imperial, mediante la autonomía cultural nacional ${ }^{8}$.

\section{La anexión de Bosnia y Herzegovina}

El mismo mes que se publicaba este artículo de Bauer, la política austríaca sobre los Balcanes terminaría con la anexión de Bosnia y Herzegovina el 6 de octubre de 1908. Ambos territorios estaban bajo administración austríaca desde 1878. El ministro de Exteriores Austro-húngaro, Aehrental, impulsaba una división de los Balcanes en una esfera occidental bajo dominio austríaco y una oriental, incluyendo Constantinopla, bajo dominio ruso. Antes de poder llegar a un acuerdo con los rusos, la revolución de los jóvenes turcos que llegó al poder en julio de 1908 anunció la convocatoria a un parlamento representativo de todos los territorios del Imperio, incluyendo Bosnia, lo que apuró los planes de los Habsburgo. Cuando Rusia puso trabas al ferrocarril de Sanjak, el gobierno de Austria-Hungría anexó ambos territorios (Roebke-Berens 1981a: 106-7).

Este acontecimiento es importante porque no hay mayor prueba para un político y teórico socialista que una anexión colonial por parte de su propio gobierno. Bauer retomaría el asunto en un importante artículo el año siguiente (Bauer 1909). En el mismo planteó la idea de una transformación de la política burguesa hacia las nacionalidades, desde la era del librecambio y las revoluciones burguesas (donde el libre mercado encontraba su corolario en la división internacional del trabajo y la asociación de pueblos libres sin tarifas aduaneras) hasta el momento donde se acabó la época revolucionaria de la burguesía y las aspiraciones nacionales sólo podrían ser realizadas en el marco de los Estados existentes (Bauer 1909: 387-388). Al mismo tiempo, reflexionaba que si en las revoluciones del siglo XIX sólo habían participado las grandes naciones históricas, la situación cambiaba en el momento en que escribía:

Hoy, las naciones sin historia también se están levantando, una después de la otra, a la existencia histórica. Si permanecieron en los márgenes durante la revolución de 1848 , en el futuro cercano su despertar puede devenir una fuerza que conduzca a grandes levantamientos (Bauer 1909: 387).

En cuanto a la política exterior, recordaba que en el contexto del siglo XIX los mismos habían puesto todo su énfasis en movilizar cualquier fuerza democrática contra Rusia, que

\footnotetext{
${ }^{8}$ El programa dominante para la cuestión nacional de los socialistas de los Balcanes era la Federación Balcánica, ver Živković y Plavšić (2003). Los socialistas austríacos no atacaban abiertamente esta idea, pero su apoyo fue tibio y no apoyaban la independencia de los pueblos eslavos de Austria para sumarse a esta federación (Roebke-Berens 1981a: 123).
} 
era considerada la cuna de la reacción y dominaba casi como estados vasallos a Prusia y Austria, arbitrando entre ellos. En este marco podía entenderse que la primera máxima práctica para Marx y Engels implicara el enfrentamiento contra Rusia. Dado el debilitamiento de Rusia este planteo perdía prioridad, aunque seguía siendo importante para evitar que los eslavos de Austria se vieran tentados por el Pan-eslavismo, al que Bauer observaba con hostilidad dada su insistencia en que la mejor alternativa para estos pueblos era la autonomía cultural nacional en el marco del Imperio (Bauer 1909: 389-391).

En cuanto al ejército, planteaba que las demandas tradicionales de Marx y Engels, retomadas por la Social Democracia alemana, habían sido la oposición al ejército profesional y la demanda de una milicia ciudadana, que dificultara el uso del ejército como instrumento reaccionario (Bauer 1909: 391). Esto perdía vigencia; en el momento era necesario oponerse al militarismo mismo: los gastos militares empeoraban las condiciones de vida de la clase trabajadora en la medida que eran pagados con impuestos indirectos, e incluso dificultaban el crecimiento del capital. La lucha por la limitación del armamento debía ser una parte constitutiva de la política de la Social Democracia (Bauer 1909: 394).

Esta demanda de desarme planteada por Bauer entroncaba con la posición que fueron desarrollando varios teóricos del Partido Social Demócrata de Alemania (principalmente Kautsky) que rompieron con el ala izquierda (encabezada por Rosa Luxemburg) a partir de 1910 para ser conocidos como la fracción de Centro. La misma tendría fuertes vínculos con los Austro-marxistas, y enfatizaría el rol de los acuerdos internacionales de desarme como medio para evitar la guerra. Una resolución en este sentido se aprobó en el Congreso de la Segunda Internacional en Copenhague en 1910 (Riddell 1984: 70), sólo para iniciar una fuerte polémica entre las alas de Centro y de Izquierda del socialismo alemán, donde esta última atacaba como utópica cualquier perspectiva de desarme llevada adelante por parte de los gobiernos imperialistas, y reafirmaba la demanda de la milicia (Day y Gaido: 63-67). El contexto del debate era si la carrera armamentista era una necesidad del capitalismo de la época o era una política opcional de la burguesía que podía ser revertida, por lo que no se trataba sólo de un estrecho debate de táctica sino que implicaba concepciones sobre la naturaleza misma del imperialismo.

Por último, en relación a la Triple Alianza entre Alemania, Austria-Hungría e Italia planteaba:

debemos oponernos también a cualquier intento de poner las fuerzas de los pueblos de Austria al servicio del imperialismo extranjero. No podemos demandar la disolución de la Triple Alianza (...) Mas debemos ciertamente demandar que la Triple Alianza se limite a su objetivo original - la defensa contra un ataque ruso (Bauer 1909: 395).

Bauer implicaba que la alianza con Alemania y la política de expansión en los Balcanes de Austria estaba implicando al país en una política imperialista. Eso puede parecer algo evidente, pero Bauer estuvo prácticamente solo dentro de la Social Democracia austríaca al realizar este planteo. Importantes líderes del partido como Adler y Renner, si bien 
criticaron el tiempo y la forma de la anexión, negaron que fuera un acto imperialista y atacaron casi por igual la posición serbia. De hecho, Adler ni siquiera cuestionó el derecho a anexionarse las provincias. La propuesta del grupo parlamentario Social Demócrata hacia estas provincias era otorgarles sufragio universal y autonomía cultural dentro del Imperio (Roebke-Berens 1981a). La cautelosa posición de Bauer aparece como una propuesta de izquierda dentro de la Social Democracia austríaca.

Los posicionamientos sobre el involucramiento externo de Austria tenían estrecha relación con la problemática interior de las nacionalidades, en la medida que tanto fuera como dentro del Imperio recrudecían los conflictos entre los austro-alemanes y las distintas etnias eslavas. Poco tiempo después de la anexión de Bosnia, el reforzamiento del conflicto nacional en los parlamentos de Austria alcanzó a la Social Democracia, con el recrudecimiento de un conflicto entre checos y alemanes por la autonomía sindical. Como continuación del debate de 1905 los checos reclamaron, con creciente fuerza a partir de 1909, extender el principio federal del partido a los sindicatos, es decir, tener el derecho a organizar sindicatos checos separados, agrupados en centrales independientes. Esta vez los sindicatos checos contaron con un decidido apoyo del partido checo, y acompañaron sus protestas ante los sindicalistas austro-alemanes con una campaña para atraer más sindicatos checos a sus comisiones independientes, incluyendo una campaña en Moravia que culminó con la división nacional de la mayor parte de los sindicatos de esa región, que hasta entonces habían permanecido unificados (Knapp 1980: 153-165).

Bauer miraba con creciente preocupación estos conflictos nacionales, y tuvo una posición conciliadora intentando evitar una ruptura. Ya en 1909 había buscado un entendimiento común con el líder checo Bohumir Smeral. En la correspondencia que mantuvieron en 1909 intentaron aunar posiciones tácticas ante los debates partidarios (Thomas 1976: 8990). En 1910, con la pelea ya abierta, Bauer escribió un panfleto donde desarrollaba una propuesta de conciliación: los sindicatos debían tener en cuenta las divisiones nacionales, otorgándole a cada nacionalidad dentro de los sindicatos cierta autonomía. Esto sólo podía llevarse adelante si la Comisión Sindical Austríaca modificaba los estatutos de los sindicatos y si los checos disolvían sus sindicatos separados (Bauer 1912a). Esta propuesta no conformó a ninguno de los bandos (Knapp 1980: 166), pero distinguió a Bauer como el único líder alemán que estaba dispuesto a ceder algo para alcanzar un entendimiento con los checos.

Este conflicto se llevó al terreno de la Internacional, donde en el Congreso de Copenhague de 1910 los separatistas checos fueron condenados. Esto provocó que el partido checo rompiera con el partido Pan-Austríaco, con la separación a su vez de un pequeño partido "centralista" checo opuesto a la secesión sindical, que permaneció dentro del partido PanAustríaco (Joll 1974: 114-5). Esto implicó el fin definitivo de la alianza entre los dos partidos nacionales más grandes e importantes de la Social Democracia de Austria. 


\section{Las perspectivas de una guerra europea}

El estallido de la Primera Guerra de los Balcanes generó un reacomodamiento político de los socialistas austríacos, que debatieron sobre el tema en un congreso partidario, entre octubre y noviembre de 1912. Adler enfatizó que la Social Democracia austríaca apoyaba la lucha de los pueblos de los Balcanes, pero que no acompañaba ningún objetivo de estos pueblos que pudiera amenazar la integridad territorial de Austria-Hungría. La política anterior de los socialistas había sido apoyar el status quo en los Balcanes. Bauer, representando una posición algo más a la izquierda, tendía a enfatizar con más fuerza las causas de la guerra asociadas a la intervención imperialista, así como las pretensiones expansionistas de Austria-Hungría. En este marco, por primera vez Bauer expresó dudas sobre si la existencia de la Doble Monarquía merecía el apoyo de los socialistas. En contraste, varios líderes Social Demócratas austro-alemanes expresaron posiciones aún más a la derecha que Adler, relativizando el apoyo a los estados balcánicos por el temor de que cayeran bajo influencia rusa, tal como Karl Renner, o directamente analizando el problema bajo una óptica nacionalista alemana, al cuestionar la intervención de Austria no por motivos antiimperialistas sino por el problema que implicaba para la monarquía sumar súbditos no alemanes, tal como Karl Leuthner (Roebke-Berens 1981b: 20-21).

En un libro publicado en Berlín en noviembre de 1912 Bauer analizó la guerra en los Balcanes a partir del conflicto entre los distintos intereses imperialistas implicados, enfatizando el apoyo continuado del imperialismo alemán al Imperio Otomano para coartar el poder británico en esa región. Austria permanentemente había intentado recortar el poder serbio durante la guerra, apoyando la independencia de Albania y negociando el reconocimiento de las conquistas serbias a cambio de un tratado comercial y la garantía de poder construir un ferrocarril hasta Salónica. La situación de tensión con Serbia sólo podía llevar a mayores conflictos en el futuro. En un libro orientado a los lectores alemanes, Bauer enfatizaba la necesidad de luchar para que Alemania buscara un entendimiento con Francia y Gran Bretaña (Bauer 1912).

Las posiciones posteriores de Bauer deben ser evaluadas tanto desde este marco nacional, como desde el marco internacional. El manifiesto del Congreso Extraordinario de la Internacional Socialista en Basle, realizado en diciembre de 1912, dio aprobación internacional a la política exterior de Adler hacia los Balcanes y, en el marco de un tono alarmista por la amenaza de guerra, planteó que el esfuerzo de la Internacional debía orientarse a luchar contra el antagonismo entre los tres grandes poderes imperialistas de Francia, Alemania y Gran Bretaña (Manifesto of the International Congress at Basel 1912).

De esta manera, en el terreno nacional la política de Bauer puede ser considerada como a la izquierda de parte importante de su partido, en el sentido de tener un escepticismo creciente hacia la supervivencia de la doble monarquía y una postura más crítica frente a su 
gobierno y sus fines. Sin embargo, en el terreno internacional su posición era parte del clima general de alarma que rodeó al Congreso de Basle.

Dicho esto, analicemos su evolución posterior en el marco del socialismo europeo. En la opinión de Haupt, hacia marzo de 1913 una nueva opinión se asentó en la mayor parte de los líderes socialistas. Ésta planteaba que con el fin de la primera crisis en los Balcanes se entraba entrando en un período de reacercamiento entre los principales poderes capitalistas, donde el peligro de guerra disminuía. El autor llama a esto la "ilusión de deténte". Las tareas de la Social Democracia en este período debían encaminarse a prolongar este entendimiento entre las potencias imperialistas y a resolver las causas de disputa entre las mismas, con el fin de luchar contra el peligro de la guerra. En este marco, la Segunda Guerra Balcánica fue interpretada como un rebote de la crisis anterior, de importancia regional y sin consecuencias de peso para el resto de Europa, como puede verse en la correspondencia entre el secretario del Buró Socialista Internacional y los partidos de los Balcanes, Austria y Francia (Haupt 1972: 103-108). Por supuesto, este pronóstico se probaría equivocado: la Primera Guerra Mundial comenzó justamente por un conflicto entre Serbia y Austria-Hungría.

Bauer no participó de esta "ilusión de deténte". En un artículo publicado sobre la Segunda Guerra de los Balcanes (junio-julio de 1913), hizo un análisis pesimista del futuro de Austria-Hungría. Interpretaba el resultado de la Segunda Guerra Balcánica, donde Serbia había incrementado enormemente su influencia a expensas de Bulgaria, y donde el apoyo de Rusia había pasado definitivamente a Serbia, como un aumento de la influencia rusa en los Balcanes, que incrementaba las posibilidades de conflicto con Austria-Hungría. También expresó un pronóstico, que se probaría equivocado, de que Alemania podría elegir debilitar la alianza con Austria para recostarse en el poder más efectivo de Rusia. Sin embargo, su planteo dominante era que en este momento de creciente influencia rusa en los Balcanes, y donde dentro de Austria crecía el nacionalismo polaco, rutenio, y de los eslavos del sur, o el Estado era rápidamente reformado o desaparecería (1913b, citado en Roebke-Berens 1981b: 24-25).

\section{Conclusiones sobre los planteos de Bauer en torno a la política de Austria}

Las posiciones de Bauer en este período son complejas y han generado apreciaciones contradictorias en la bibliografía sobre su papel. Haupt ha enfatizado sus diferencias con la línea de su partido a partir de 1908 (Haupt y Löwy 1980: 69), y su planteo sobre los "pueblos sin historia" en relación con los Balcanes y la cuestión eslava, repetido en 1912 como base de avanzada de la nueva posición del socialismo internacional a favor de la emancipación de los pueblos balcánicos (Haupt 1972: 71-73). Otros autores han destacado que la política de autonomía nacional cultural escondía un apoyo soterrado a la dominación alemana sobre Austria, y que Bauer sólo apoyó la autodeterminación tanto de los alemanes 
como de los pueblos eslavos en 1918, cuando era evidente que la doble monarquía estaba condenada (Introducción de Plavšić, en Živković y Plavšić 2003: 128-129).

Nuestro propio balance es que Bauer en algunos aspectos mantuvo la línea partidaria tradicional y en otros se diferenció. Al igual que para la mayoría del Partido, su política hacia Austria y el imperialismo consistió en: 1) apoyar la permanencia del Estado austríaco, reformado a través de la autonomía nacional cultural; 2) apoyar la permanencia de la Triple Alianza; 3) oponerse al involucramiento de Austria en conquistas balcánicas. En relación a las medidas para evitar la guerra, coincidió con los Centristas alemanes en la apuesta por el desarme, defendiendo medios pacíficos para conseguirlo (el trabajo parlamentario, los mítines y manifestaciones). Su principal diferencia con la política general de su partido fue su tesis del "despertar de los pueblos sin historia". Si bien esto no implicó el apoyo a una política independentista de los eslavos que vivían dentro de la doble monarquía, sí produjo una condena más abierta de su parte a la política balcánica de Austria. A su vez, su preocupación por los crecientes conflictos nacionales lo llevó a ser prácticamente la única voz conciliadora con los separatistas checos en 1910. Por último, expresó crecientes dudas a partir de 1912 sobre las posibilidades de supervivencia del Estado austríaco.

Nuestra conclusión es que Bauer participaba de las concepciones Centristas en lo esencial, tanto en los medios de lucha contra la guerra (donde acordaba con los Centristas alemanes como Kautsky) como en el análisis de la situación austríaca, siendo ésta a su vez la línea predominante del partido dirigido por Víctor Adler. Su crítica de algunos aspectos importantes de la misma no condujo a una revisión general de su postura.

\section{Conclusión}

Hemos analizado los aspectos más importantes de las teorías de Bauer sobre las crisis, la cuestión nacional, la acumulación de capital y el imperialismo. Nuestra visión es que existe una conexión entre todos estos aspectos. Como hemos visto, su teoría de las crisis no superaba una exposición de las fases del ciclo industrial del capitalismo, la alternancia de prosperidad y depresión, descartando cualquier posibilidad de crisis general o sistémica. Esta misma idea lo llevó a concebir un análisis del imperialismo que, si bien se basaba en observaciones penetrantes sobre el nuevo papel de los trusts y cárteles, su relación con el proteccionismo, y la necesidad que creaba de exportaciones de capital y mercancías, lo concebía a su vez como un medio de regular el ajuste entre tiempo de producción y tiempo de circulación de mercancías. Para Bauer estos desajustes por un lado pueden resolverse dentro de la propia metrópoli, y por otro lado la política imperialista no los reproduce como contradicciones más graves en un nivel superior: sólo atenúa sus efectos o acelera su resolución. Su reconocimiento de la teoría de Hilferding y la importancia de la exportación de capitales no lo movería de este marco "neo-armonicista". A diferencia de quienes recuperaron a Hilferding desde la izquierda Social Demócrata (tales como Pannekoek 1913 y Lenin 1916), subrayando que la exportación de capitales era la base

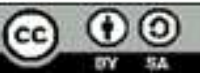


para analizar el imperialismo como un fenómeno necesario, Bauer no cambiaría lo esencial de su visión del imperialismo, repetida en su reseña sobre La Acumulación de Capital de Rosa Luxemburg. Su política sobre el involucramiento imperialista de Austria puede ser caracterizada como un Centrismo de izquierda, en general afín a la línea de la dirección de su partido, con diferencias que se basaban en un antiimperialismo más coherente, en un cuestionamiento parcial del germano-centrismo de su partido (visible en sus posiciones sobre la ruptura con los checos) y en su oposición a la "ilusión de deténte" que se apoderó del socialismo europeo a partir de marzo de 1913. Estos elementos, sin embargo, no produjeron diferenciaciones significativas en sus recomendaciones para la política sobre las nacionalidades y la política exterior de Austria más allá de un creciente pesimismo sobre la supervivencia de dicho Estado y las posibilidades de una guerra europea. Si bien no podemos decir que exista una relación mecánica entre una teoría general del imperialismo y sus consecuencias políticas prácticas, podemos establecer en el caso de Bauer las siguientes correspondencias y contradicciones: una teoría del imperialismo que tendía a verlo como un medio de ampliación de la acumulación, de carácter no necesario, favoreció inicialmente una mirada de las contradicciones nacionales e imperiales como superables a través de un nuevo esquema estatal; cuando la fuerza de estas contradicciones se hizo evidente prácticamente, como él mismo reconoció en forma creciente entre 19081913, esto no lo hizo modificar su teoría general del imperialismo, como prueba su artículo de 1913 sobre La acumulación de Capital de Rosa Luxemburg.

\section{Bibliografía y documentos}

Bauer, Otto (1904), 'Marx’ Theorie der Wirtschaftskrisen', Die Neue Zeit, 23, 1: 133-148,164-70. Bauer, Otto (1907) [2000], The Question of Nationalities and Social Democracy, edited by Ephraim J. Nimni, translated by Joseph O’Donnell, Minneapolis: University of Minnesota Press.

Bauer, Otto (1908), 'Österreich und der Imperialismus', Der Kampf, 2, 1, (October): 17-22. Versión inglesa usada en Day y Gaido (2012): 373-382.

Bauer, Otto (1909), 'Nationale und internationale Gesichtspunkte in der auswärtigen Politik', Der Kampf, 2, 12 (September): 535-41. Versión inglesa usada en Day y Gaido (2012): 383-396.

Bauer, Otto (1910a), Krieg oder Frieden in den Gewerkschaften? Viena: Brand und co.

Bauer, Otto (1910b), 'Das Finanzkapital', Der Kampf, 3 (June): 391-7. Versión inglesa usada en Day y Gaido (2012): 413-424.

Bauer, Otto [Heinrich Weber] (1912a), "Der Sozialismus und der Krieg," Der Kampf, 6 (October 1912 - September 1913).

Bauer, Otto (1912b), Der Balkankrieg und der deutsche Weltpolitik (Berlin, Noviembre 1912).

Bauer, Otto (1913a), 'Die Akkumulation des Kapitals', Die Neue Zeit, 31, 1: 831-8, 862-74. Versión inglesa usada en Day y Gaido (2012):713-744.

Bauer, Otto (1913b), "Der zweite Balkankrieg," Der Kampf, 6 (Octubre 1912 - Septiembre 1913).

Day, Richard B. y Gaido, Daniel (2012), Discovering Imperialism: Social Democracy to World War I, Leiden: Brill.

Grossmann, Henryk (1929) [1981] La ley de la acumulación y del derrumbe del sistema capitalista, México: Siglo XXI. 
Haupt, Georges (1972), Socialism and the Great War: The Collapse of the Second International, Oxford: Clarendon Press.

Haupt, Georges y Löwy, Michael (1980), Los marxistas y la cuestión nacional, Barcelona: Fontamara.

Hilferding, Rudolf (1910) [1981], Finance Capital: A Study of the Latest Phase of Capitalist Development, editado con una introducción de Tom Bottomore, London: Routledge \& K. Paul. Joll James (1974). The Second International, 1889-1914. Boston: Routledge \& Kegan Paul. Kautsky, Karl (1902), 'Krisentheorien', Die Neue Zeit, 20, 2: 37-47, 76-81, 110-18, 133-43. Kautsky, Karl (1910), "Finanzkapital und Krisen”, Marx-Studien, Vol. III, Viena. Traducción castellana en: En Defensa del Marxismo, 37: 51-82

Karski [Marchlewski, Julian] (1910), 'Rudolf Hilferding, Das Finanzkapital: Eine Studie über die jüngste Entwicklung des Kapitalismus', Leipziger Volkszeitung, 198 (27 August).

Knapp, Vincent J. (1980), Austrian Social Democracy, 1889-1914, Washington: University Press of America.

Kogan, Arthur G. (1949), "The Social Democrats and the Conflict of Nationalities in the Habsburg Monarchy", The Journal of Modern History, Vol. 21, No. 3, Sep., 1949: 204-217.

Lenin, Vladimir I. (1916) [1970], Imperialism, the Highest Stage of Capitalism: A Popular Outline, Peking: Foreign Languages Press.

Luxemburg, Rosa (1913) [1951], La acumulación del capital, México: Grijalbo.

Luxemburg, Rosa (1921) [1971], The Accumulation of Capital - An Anti-Critique, or What the Epigones Have Made of Marx's Theory, in Nikolai I. Bukharin and Rosa Luxemburg, Imperialism and the Accumulation of Capital, London: Penguin.

Marx, Karl (1894) [1977], El capital: Crítica de economía política, Tomo III: El Proceso global de la producción capitalista, Buenos Aires: Siglo XXI.

"Manifesto of the International Congress at Basel" (1912), publicado en British Socialist, 25 December 1912: 556-560.

Renner, Karl (1902), Der Kampf der osterreichischsen Nationen um den Staat, Leipzig.

Pannekoek, Anton (1913), 'Rosa Luxemburg: Die Akkumulation des Kapitals. Ein Beitrag zur ökonomischen Erklärung des Imperialismus', Bremer Bürger-Zeitung, 24-5 (29-30 enero 1913), en Day y Gaido 2012, pp. 675-693.

Riddell, John (ed.) (1984), Lenin's Struggle for a Revolutionary International: Documents, 19071916: The Preparatory Years, New York: Monad Press.

Roebke-Berens, Ruth (1981a),"Austrian Social Democratic Foreign Policy and the Bosnian Crisis of 1908", Austrian History Yearbook 17: 104-123.

Roebke-Berens, Ruth (1981b), "Austrian Social Democratic Peace Policy and the Balkan Crises of 1912-1913", Peace \& Change 7.1-2: 17-27.

Rosdolsky, Roman (2004), Génesis y estructura de 'El capital' de Marx, México: Siglo XXI.

Thomas, Trevor Vaughan (1976), "Bohumil Smeral and the Czech Question 1904-14", Journal of Contemporary History, Vol. 11, No. 2/3, (Jul., 1976): 79-98.

Tudor H. and J.M. Tudor (eds.) (1988), Marxism and Social Democracy: The Revisionist Debate 1896-1898, Cambridge University Press.

Tugan-Baranowsky, Michael von (1901), Studien zur Theorie und Geschichte der Handelskrisen in England, Aalen: Scientia Verlag, 1969. Reprint of the Jena ed.

Živković, Andreja y Plavšić, Dragan (eds) (2003), “The Balkan Socialist Tradition, 1871-1915”, Revolutionary History, Vol. 8, No. 3. 